\title{
Strategic application of radiotherapy for hepatocellular carcinoma
}

\author{
Seo Hee Choi and Jinsil Seong \\ Department of Radiation Oncology, Yonsei Cancer Center, Yonsei University College of Medicine, Seoul, Korea
}

With increasing clinical use, radiotherapy (RT) has been considered reliable and effective method for hepatocellular carcinoma (HCC) treatment, depending on extent of disease and patient characteristics. RT for HCC can improve therapeutic outcomes through excellent local control, downstaging, conversion from unresectable to resectable status, and treatments of unresectable HCCs with vessel invasion or multiple intrahepatic metastases. In addition, further development of modern RT technologies, including image-guided radiotherapy (IGRT), intensity-modulated radiotherapy (IMRT), and stereotactic body radiotherapy, has expanded the indication of RT. An essential feature of IGRT is that it allows image guidance therapy through in-room images obtained during radiation delivery. Compared with 3D-conformal RT, distinctions of IMRT are inverse treatment planning process and use of a large number of treatment fields or subfields, which provide high precision and exquisitely conformal dose distribution. These modern RT techniques allow more precise treatment by reducing inter- and intra-fractional errors resulting from daily changes and irradiated dose at surrounding normal tissues. More recently, particle therapy has been actively investigated to improve effectiveness of RT. This review discusses modern RT strategies for HCC, as well as optimal selection of RT in multimodal approach for HCC. (Clin Mol Hepatol 2018;24:114-134)

Keywords: Hepatocellular carcinoma; Radiotherapy; Image-guided radiation therapy

\section{INTRODUCTION}

Traditionally, the role of radiotherapy (RT) for hepatocellular carcinoma (HCC) has been limited due to the relatively low liver tolerance to radiation, although many are not candidates for curative treatment or not adequately treated with transarterial chemoembolization (TACE), radiofrequency ablation (RFA), or sorafenib. Well- known Barcelona Clinic Liver Cancer (BCLC) guidelines for HCC did not recommend RT as a primary treatment option for all stages of HCC. In clinical guidelines of the European Association for the Study of the Liver and European Organization for Research and Treatment of Cancer (EASL-EORTC), use of external beam radiotherapy (EBRT) was also limited due to the possibility of radiationinduced liver disease (RILD), and reasons for the benefits of three-

\footnotetext{
Abbreviations:

BCLC, Barcelona Clinic Liver Cancer; CPT, Charged particle therapy; CR, complete response; CBCT, cone-beam CT; EASL-EORTC, European Association for the Study of the Liver and European Organization for Research and Treatment of Cancer; EBRT, external beam radiotherapy; FFLP, freedom from local progression; Gy, Gray; GyE, Gray-equivalent; HCC, hepatocellular carcinoma; IGRT, Imageguided radiotherapy; IMRT, Intensity-modulated radiotherapy; LET, linear energy transfer; mUICC, modified Union for International Cancer Control; MLC, multileaf collimator; NCCN, National Comprehensive Cancer Network; OS, overall survival; PR, partial response; PVTT, portal vein tumor thrombosis; PFS, progression-free survival; PBT, proton beam therapy; RILD, radiation-induced liver disease; RFA, radiofrequency ablation; $\mathrm{RT}$, radiotherapy; SBRT, stereotactic body radiotherapy; 3D-CRT, three-dimensional conformal radiotherapy; TACE, transarterial chemoembolization
}

\section{Corresponding author : Jinsil Seong}

Department of Radiation Oncology, Yonsei Cancer Center, Yonsei University College of Medicine, 50-1 Yonsei-ro, Seodaemun-gu, Seoul 03722, Korea

Tel: +82-2-2228-8111, Fax: +82-2-2227-7823

Email:jsseong@yuhs.ac

https://orcid.org/0000-0003-1794-5951 
dimensional conformal radiotherapy (3D-CRT) have only been shown in uncontrolled studies.

However, with increasing clinical use, RT has been considered reliable and effective for HCC treatment, depending on each stage. In addition, further development of modern RT technologies, including intensity-modulated radiotherapy (IMRT), image-guided radiotherapy (IGRT), and stereotactic body radiotherapy (SBRT), have expanded the indication of RT. In comparison to 3D-CRT, distinctions of IMRT include inverse treatment planning process and use of a large number of treatment fields or subfields, which provide high precision and exquisitely conformal dose distribution. Furthermore, the addition of multileaf collimator (MLC) enables non-uniform intensity profiles in various ways.

The role of RT is documented in several clinical guidelines. According to the most recent National Comprehensive Cancer Network (NCCN) guideline', EBRT is suggested as a locoregional treatment option for patients with unresectable HCC who are ineligible for transplantation, inoperable due to comorbidities, or those who have a local disease with/without minimal extrahepatic disease, with evidence level of 2B. Locoregional therapy, including EBRT, is also suggested as a treatment option for patients who have operable tumors, although resection is the preferred treatment. The guideline also mentions feasibility of modern RT and indications for SBRT. Korean Liver Cancer Study Group (KLCSG) has published the first comprehensive guidelines in 2003 with details regarding $R T$ indication, and these guidelines have been updated recently in 2014. ${ }^{2}$ The KLCSG guideline provides multiple treatment suggestions for each stage based on the modified Union for International Cancer Control (mUICC) staging system, and lists the best options and alternatives. Based on recent perspectives, KLCSG is currently revising its 2014 guideline and discussing ways to further refine and expand the role of RT.

In this review, we describe the technical aspects of modern RT techniques for $\mathrm{HCC}$ along with their clinical applications in HCC, mainly according to the mUICC staging system. Furthermore, we introduce recent trends of RT, such as particle therapy.

\section{MODERN RADIOTHERAPY TECHNIQUES}

\section{Intensity-modulated radiotherapy (IMRT)}

Development of RT mainly focuses on improving two factors: accuracy and precision. Accuracy of RT implies that radiation can be delivered to the correct location each time, despite various uncer- tainties between the time of radiation treatment planning and the time of actual treatment. Precision of RT means the ability to control distribution of radiation to make sure that prescribed dose is administered exactly to tumor site, and that radiation is not delivered to surrounding normal tissues.

In the past, it was possible to perform treatment using two-dimensional fluoroscopic imaging plan and estimate radiation distribution in only one direction ("2D-RT"). Based on the development of computer engineering and radiology, computerized tomography (CT) images were used in planning simulation, while considering the three-dimensional positional relationship between tumor and surrounding normal tissues, in addition to more conformal treatments ("3D-CRT"). IMRT is the most advanced 3D-conformal treatment technique. It modulates the intensity of radiation delivered in each treatment direction, and selectively delivers the desired dose of radiation only to the tumor site while minimizing the amount of radiation entering normal tissue around tumor (Fig. 1). The core of this treatment technique is the so-called "inverse treatment planning," in which the physician sets the ideal dose of targets and normal organs, and relative importance for tumor and surrounding organs in advance. Then, the machine computes and determines numbers and angles of beams. In the past, physicians performed target contouring and determined numbers and angles of beams, and then the machine performed RT ("Forward planning") (Fig. 2).

\section{Control of respiratory motion during radiation delivery}

Another critical issue in RT for HCC is the control of respiratory motion, as the liver moves in a considerable range during respira-

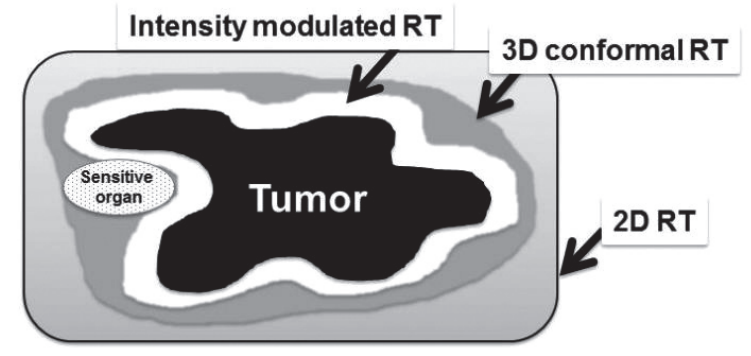

Figure 1. Comparison of treatment volumes by various radiotherapy RT technology involving 2D radiotherapy, 3D conformal radiotherapy (3DCRT), and intensity modulated radiotherapy (IMRT). IMRT is the most advanced 3D-conformal treatment technology. It modulates the intensity of radiation delivered in each treatment direction, and selectively delivers the desired dose of radiation only to the tumor site, while minimizing the amount of radiation entering sensitive normal organs around the tumor with high precision. 


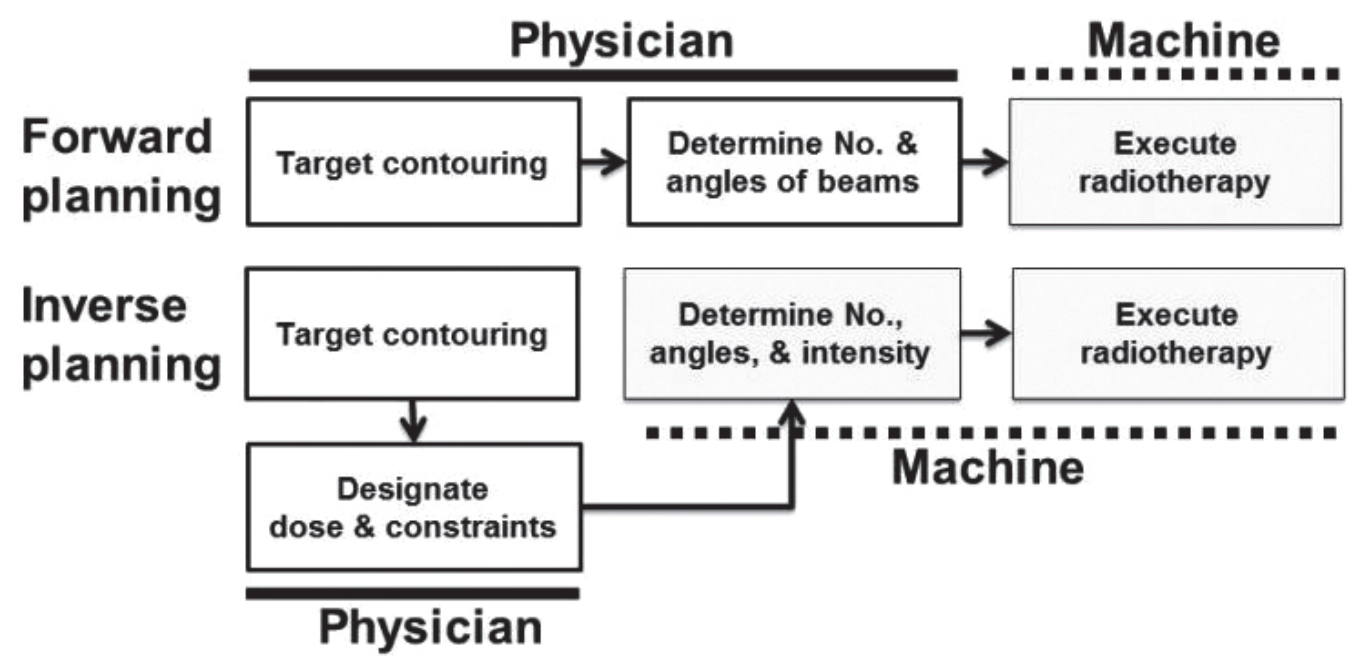

Figure 2. Concept of inverse planning of intensity modulated radiotherapy (IMRT). In the past, physicians performed target contouring and determined numbers and angles of the beams, and then the machine performed radiotherapy ("forward planning"). The core of IMRT technique is the socalled "inverse planning," in which the physician sets ideal dose of targets and normal organs, and relative importance for the tumor and surrounding organs in advance. Then, the machine computes and determines numbers and angles of the beams.

tion. There are several ways to treat a moving tumor to ensure the tumor receives intended dose while reducing the dose to surrounding normal tissue. The strategies can be classified into motion-encompassing, breath-hold, forced shallow breathing with abdominal compression, respiratory gating, and real-time tumor tracking.

Motion-encompassing method refers to the covering of all possible positions of moving tumor through the entire breathing cycle using 4D-CT images. Subsequently, a large volume of normal tissue may be irradiated. Breath-hold method refers to letting the patient hold his or her breaths for a few seconds under deep inspiration, and then deliver radiation only when the liver is in a certain position. Forced shallow breathing is using a particular external device, such as an abdominal compressor, to allow the patient to breathe shallow during radiation therapy. Although breath-hold and forced shallow breathing might result in patient discomfort or inconvenience during treatment, it can reduce respiratory motion for liver tumors and enhance accuracy.

Currently, respiratory gating and real-time tumor tracking are considered the most advanced techniques. Respiratory gating method involves turning on the radiation beam only during a specific respiratory cycle, after accurately grasping the position of tumor according to the patient's respiratory cycle in advance, using 4D-CT images.

Real-time tracking method refers to tracking the movement of tumor along respiratory cycle using the surrogate on abdominal surface or internal fiducial marker, and then delivering radiation by following tumor inside the body. No respiratory control and abdominal compression are needed. This gating method using an external breathing signal is natural, noninvasive, and radiationfree; however, potential error might be that the signal does not accurately correlate with internal target position. On the other hand, the use of internal fiducial markers is an invasive method; however, it can improve the accuracy of treatment. Currently, one of the machines that are capable of tumor tracking is the CyberKnife system. Clinical feasibility of CyberKnife system has been demonstrated in several studies, especially SBRT papers. CyberKnife SBRT has been proven to be a safe and effective noninvasive treatment for $\mathrm{HCC}^{3-7}$ CyberKnife system consists of a pair of fluoroscopes in the ceiling coupled to a small X-band linear accelerator mounted on robotic arm, which can move according to the movement of inserted fiducial markers. Patients are encouraged to undergo implantation of three or more fiducial markers in the liver parenchyma around the perimeter of tumor before treatment, which would serve as radiographic landmarks for respiratory synchrony system and image guidance technique.

\section{Image-guided radiotherapy (IGRT)}

IGRT is defined as RT that utilizes imaging to maximize accuracy throughout the entire treatment process, including precise targeting and normal tissue representation, radiation delivery, and adaptive plans for anatomic and biological changes over time for the patient. Of these, accurate target delineation, target relocalization 
to allow proper patient repositioning, and respiratory motion management have been the most challenging for patients with HCC, mainly due to the uncertain movement of the liver.

An essential feature of IGRT is that it allows image guidance therapy through in-room images obtained during radiation delivery (Fig. 3). This leads to more precise treatment by reducing inter- and intra-fractional errors that result from daily changes in the liver to bones, breathing motion, and variation in shape and position of neighboring organs. Physicians can reduce target margins and spare additional normal tissue dose using 2D or 3D image guidance techniques (helical megavoltage CT, kilovoltage cone-beam $\mathrm{CT}(\mathrm{CBCT})$, and MV CBCT), compared to in-room laser beams and skin marks (Fig. 3). Degree of error is evaluated by comparing reference images to in-room images. If the error is beyond allowable range and physicians see a need for adaptive planning, they should retake planning $\mathrm{CT}$ and restart treatment after new RT

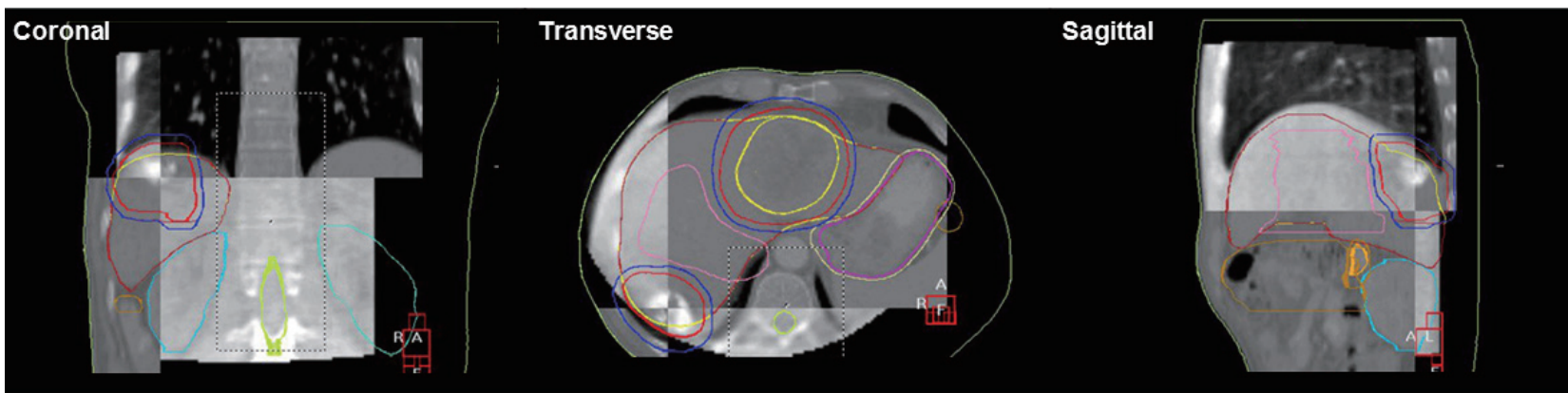

Figure 3. Illustration of image-guided radiotherapy (IGRT) with daily setup using three-dimensional volumetric imaging modality. Matching between "reference images" using three-dimensional reconstruction of planning computed tomography images and in-room cone-beam computed tomography images are performed on each day of treatment.

\section{Clinical evaluation}

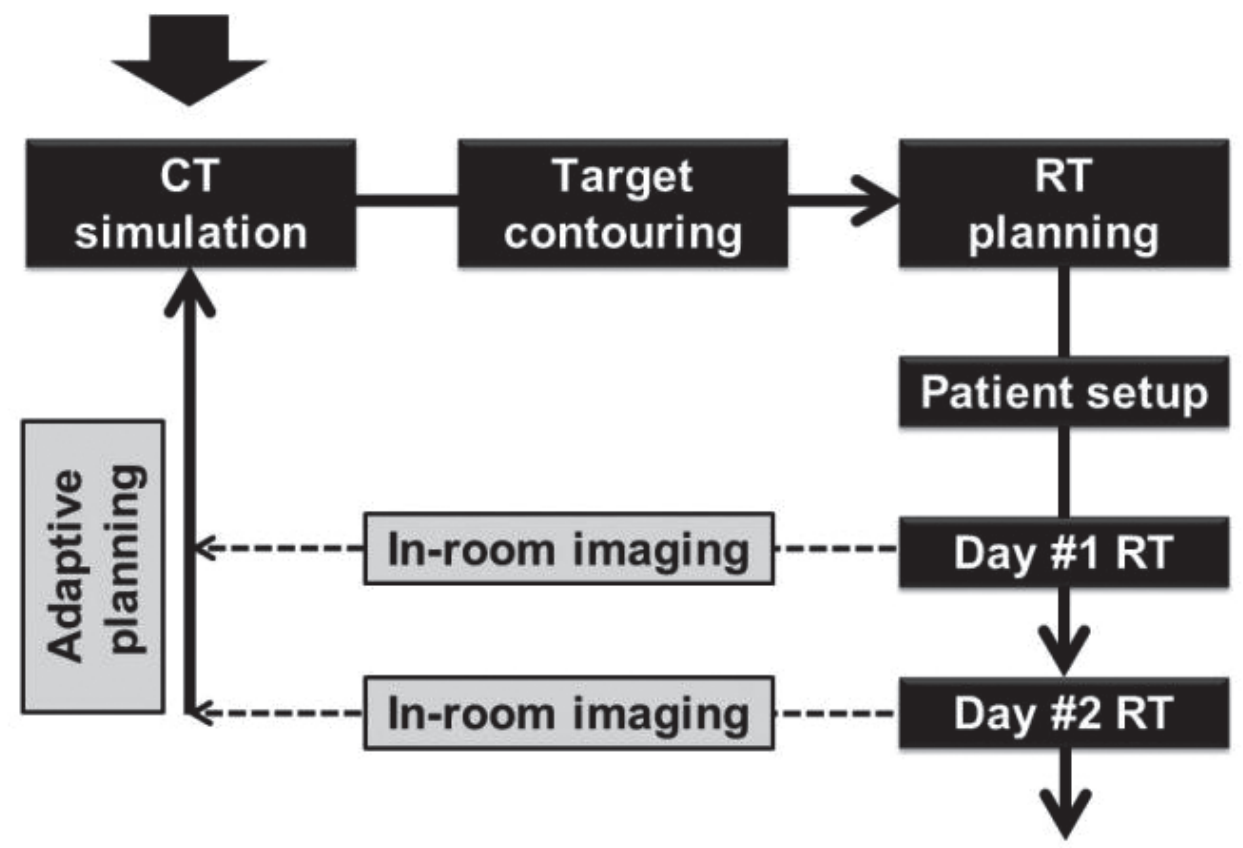

Figure 4. Workflow of image-guided radiotherapy (IGRT). An essential feature of IGRT is that it allows image guidance therapy through in-room images obtained during radiation delivery. Physicians can reduce target margins and spare additional normal tissue dose using 2D or 3D image guidance techniques (helical megavoltage CT (MVCT), kilovoltage cone-beam CT (CBCT), and MV CBCT), compared to in-room laser beams and skin marks. Degree of error is evaluated by comparing reference images with in-room images at every treatment time. If the error is beyond the allowable range and physicians sees a need for adaptive planning, they should retake a planning CT and restart treatment after new RT planning. 
planning (Fig. 4).

\section{RADIOTHERAPY FOR EARLY STAGE (mUICC STAGE I/II) HCC}

Curative therapies can improve survival in early-stage HCC patients. Resection, percutaneous ethanol injection (PEI), and RFA have been considered valid local ablative treatments. However, when the effect is limited for reasons of primary tumor location (e.g., near the liver dome, or major vessels), RT may be considered as an alternative. Also, RT may be a feasible alternative for those who are inoperable or refuse surgery.

\section{SBRT for early stage HCC}

Local high-dose RT, including SBRT, can be an appropriate alternative definitive or salvage treatment. In several prospective ${ }^{8-17}$ (Table 1) or retrospective ${ }^{3,4,18-29}$ (Table 2) papers, SBRT has been reported as a very effective, safe, and noninvasive treatment modality in primarily diagnosed or recurrent cases when size and position are acceptable. Honda Y, et al. demonstrated that SBRT combined with TACE is a safe and effective modality for locoregional treatment of small solitary primary HCC, with a $96 \%$ of high complete response (CR) rate. ${ }^{22}$ Even for huge $\mathrm{HCC} \geq 10 \mathrm{~cm}$, SBRT could be a safe and effective treatment option. Jang WI, et al. suggested that there was a positive linear relationship between SBRT dose and 2-yr local control, overall survival (OS) rates, which were highest at $>54$ Gy. ${ }^{24}$ Sometimes, SBRT was also used for portal vein tumor thrombosis (PVTT) and/or inferior vena cava tumor thrombosis ${ }^{23,27}$, $B C L C$ stage $C H C C^{27}$, or huge $\mathrm{HCC} \geq 10 \mathrm{~cm}^{28,29}$, with acceptable response rates and survival outcomes. Wahl DR, et al. compared outcomes of patients with inoperable, nonmetastatic HCCs who underwent SBRT or RFA. ${ }^{30}$ For tumors $<2 \mathrm{~cm}$, there was no significant difference between RFA and SBRT in freedom from local progression (FFLP) (HR, 2.50; 95\% Cl, 0.72 to 8.67; $P=0.15)$; however, for tumors $\geq 2 \mathrm{~cm}$, RFA was associated with significantly worse FFLP (HR, 3.35; $95 \% \mathrm{Cl}, 1.17$ to $9.62, P=0.025)$.

\section{Radiotherapy as bridging treatment before liver transplantation}

O'Connor JK, et al. reported that SBRT could be used as effective bridging treatment before liver transplantation. ${ }^{31}$ In a recent study from Toronto General Hospital ${ }^{32}$, 379 patients who underwent liv- er transplantation after SBRT $(n=36)$, TACE $(n=99)$, or RFA ( $n=244)$ were compared, to evaluate the safety and efficacy of bridging treatments. Drop-out rate and postoperative complication rates were similar between groups. The 3-year survival rate from time of transplant was 75\% in SBRT group, 75\% in TACE group, and 81\% in RFA group, which were not significantly different. This showed that SBRT might be as effective and safe as TACE or RFA, when used to maintain candidacy of patients with HCC who are on the wait-list for a transplant for the first time.

\section{RADIOTHERAPY FOR INTERMEDIATE STAGE (mUICC STAGE II/III) HCC}

In general, intermediate stage HCC is considered primarily for TACE. However, the effects of TACE may be limited if there is vascular shunting, recanalization around the tumor capsule, or development of multiple feeding vessels. TACE is contraindicated in patients with PVTT or inferior vena cava invasion, as it has potential risk of ischemic liver damage..$^{33}$ In addition, complete or massive necrosis is seldom observed following TACE, when the tumor is $>5 \mathrm{~cm}$. 34,35 In HCCs that either showed incomplete response after TACE or were unsuitable for TACE, RT can be useful as a complementary modality. ${ }^{36-39}$

\section{Radiotherapy for unresectable HCC after incomplete TACE}

In many prospective ${ }^{40-45}$ or retrospective ${ }^{36,39,46-49}$ papers, large unresectable HCCs were well treated with TACE followed by EBRT, and objective response rates (complete and partial responses) were achieved in about $63-76 \%$ of cases with $72-82 \%$ of 1 -year survival rate, which is significantly higher compared to patients without EBRT (Table 3). A recent prospective phase II multicenter study ${ }^{45}$ investigated the efficacy and toxicity of RT following incomplete TACE in unresectable HCCs. Here, patients with unresectable HCC who had viable tumor after TACE of no more than three courses were eligible, and median 54 Gy of 3D-CRT was delivered. Best objective infield response rate was achieved in $84 \%$ of patients, with $23 \%$ of $C R$ rates and $61 \%$ of partial response (PR) rates within 12 weeks post-RT. The 2-year in-field progression-free survival (PFS), overall PFS, and OS rates were $45 \%, 29 \%$, and $61 \%$, respectively. These findings demonstrate that early application of 3D-CRT can be a promising option in multimodal approaches for patients with incomplete necrosis after TACE. Meng MB, et al. performed 
Seo Hee Choi, et al.

Modern RT strategies for HCC

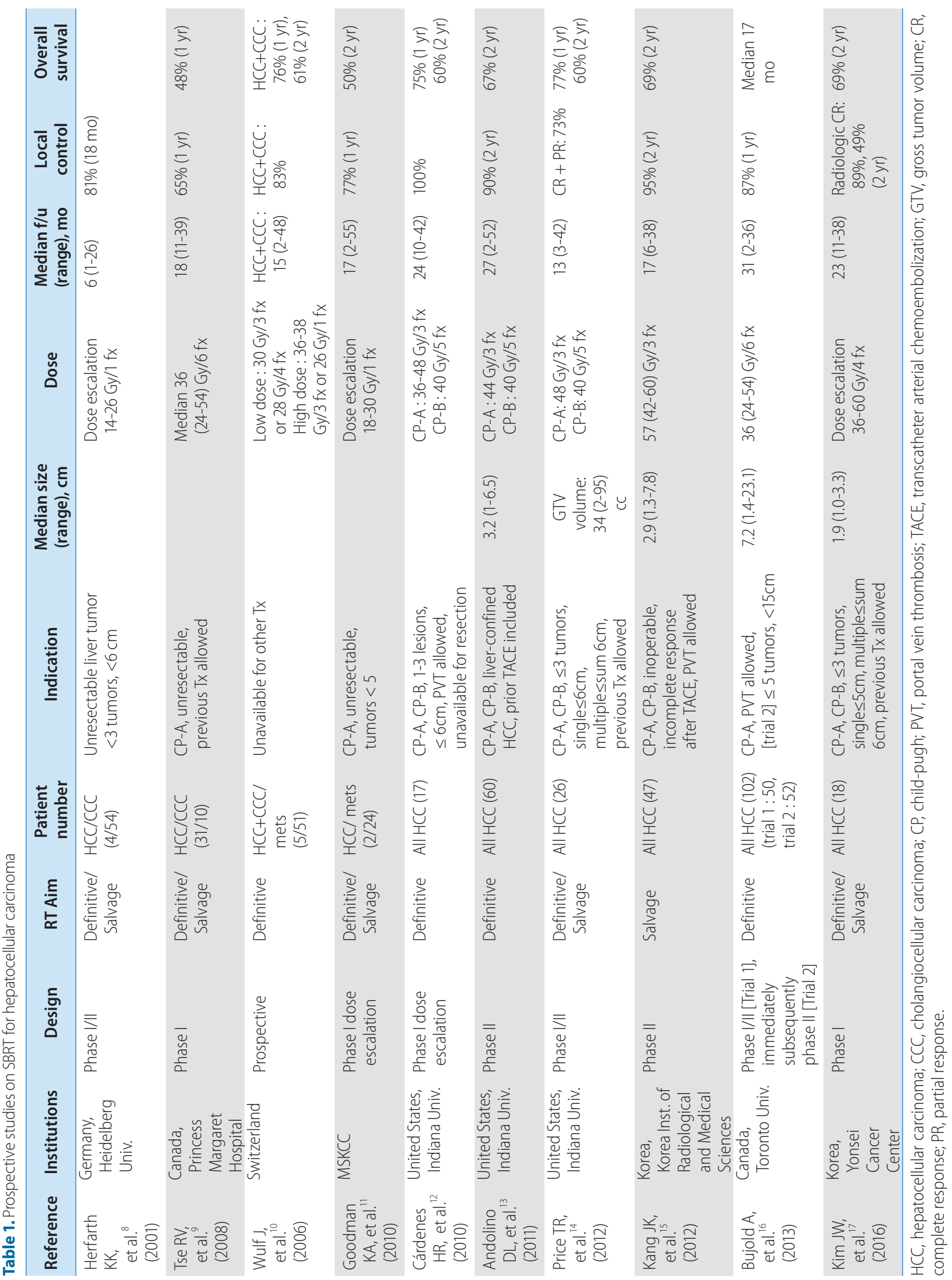




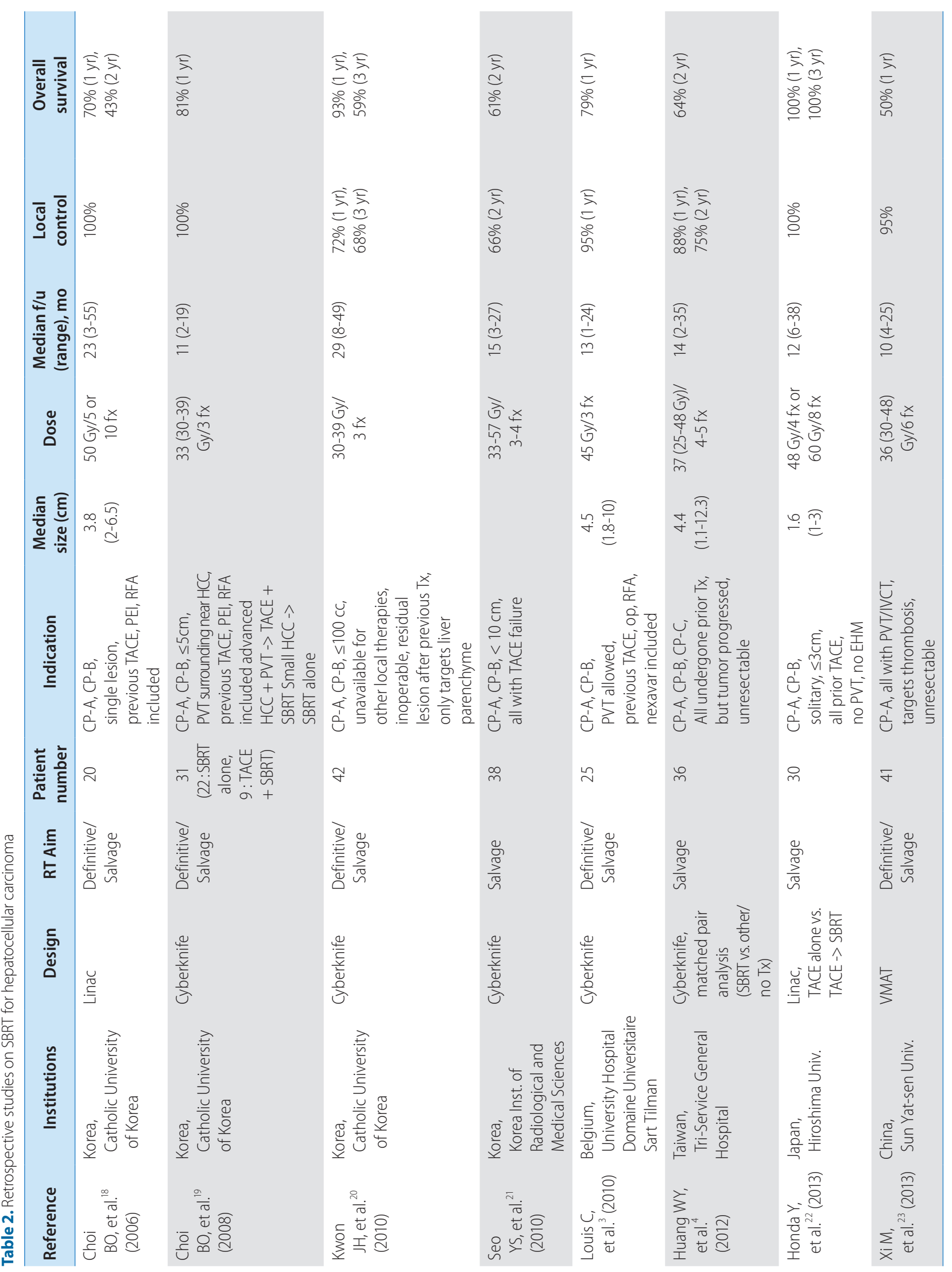


Seo Hee Choi, et al.

Modern RT strategies for HCC

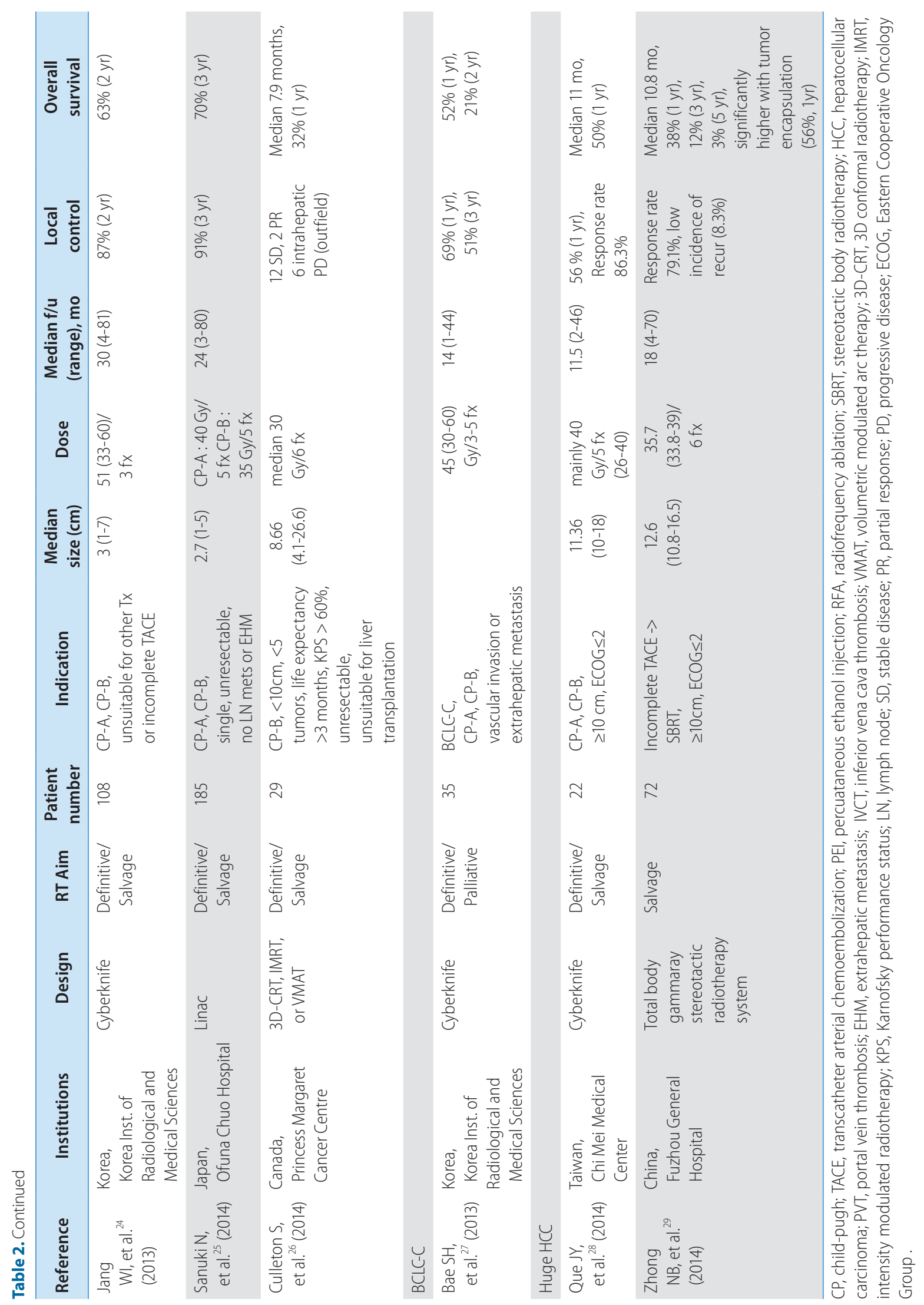




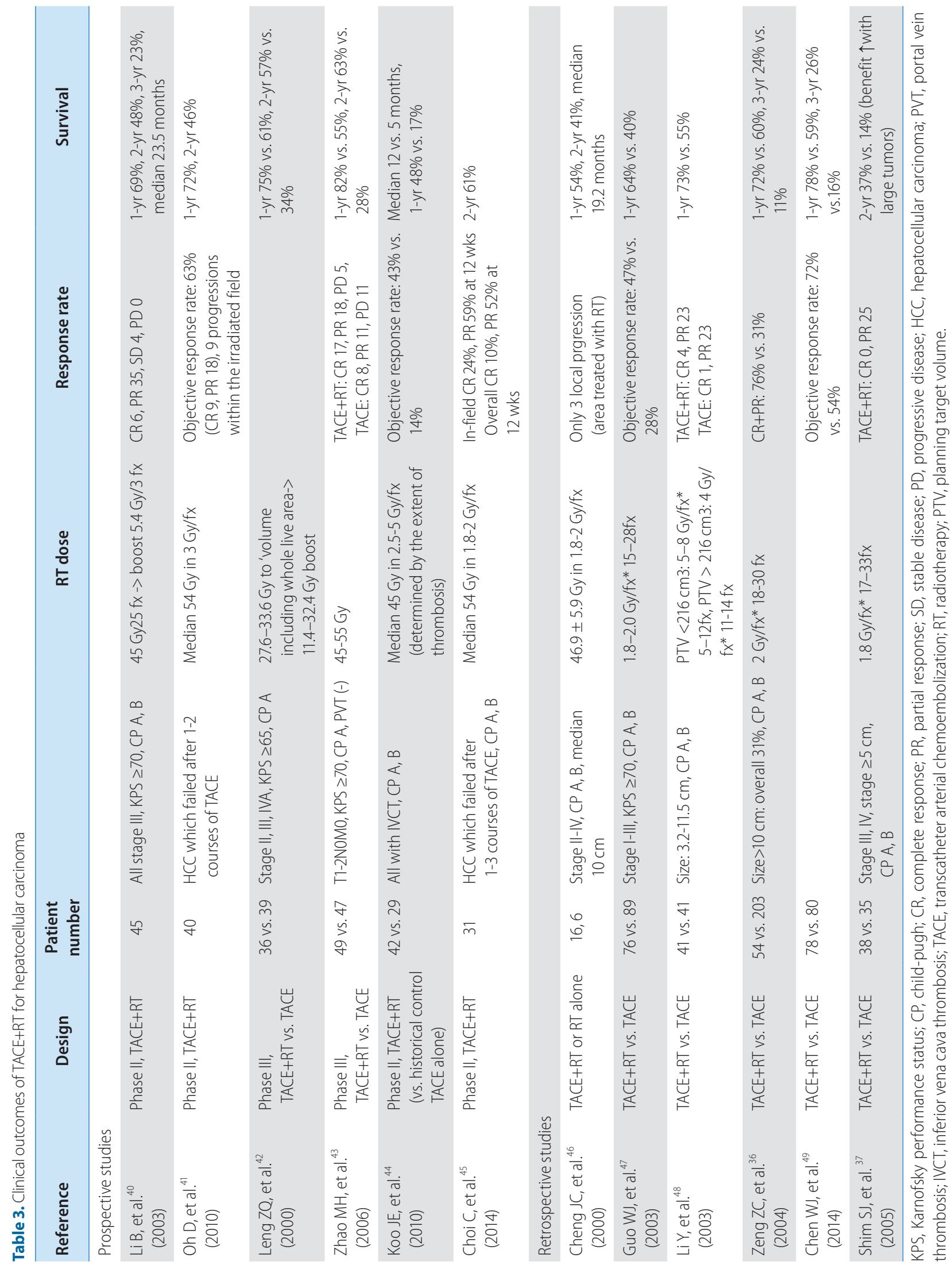


meta-analysis from five randomized controlled trials and 12 nonrandomized controlled clinical trials, which compared TACE+RT group and TACE alone group. ${ }^{50}$ TACE+RT significantly improved survival rates and $C R$ rates $(O R, 2.58 ; 95 \% \mathrm{Cl} 1.64-4.06 ; P=0.0001)$. Rates of adverse events were not significantly different, except for elevation of total bilirubin level. Other meta-analyses ${ }^{51,52}$ also presented similarly favorable outcomes with TACE+RT compared to using TACE alone.

\section{RADIOTHERAPY FOR ADVANCED STAGE (mUICC STAGE III/IV) HCC}

\section{Radiotherapy for unresectable HCC with PVTT}

For patients who are unsuitable for TACE due to PVTT, value of RT has been especially noticeable in several prospective $e^{44,53-57}$ and retrospective studies. ${ }^{38,58-67}$ About $31 \%$ to $83 \%$ of objective response rates and median OS of 7 months to 34 months in responders have been reported ${ }^{37,59,61,67,68}$ (Table 4). According to Korea's long-term follow-up data, ${ }^{59}$ authors reported clinical outcomes of patients who underwent RT for HCC with PVTT. With radiation volume including PVTT ( \pm whole HCC), median survival time was 10.6 months, and 1-year survival rate was $43 \%$. Furthermore, $3.6 \%$ of patients achieved CR and $24.3 \%$ of patients achieved PR, with $10 \%$ of grade $3-4$ hepatic toxicity and $4 \%$ of gastroduodenal complications. TACE plus RT achieved significant survival advantage in HCC with PVTT than using TACE alone, according to propensity score matching. ${ }^{69}$ Median survival time was 10.9 versus 4.1 months $(P<0.001)$ in all patients, 12.5 versus 4.4 months $(P=0.002)$ in patients with PVTT involving the right/left portal vein, and 8.9 versus 4.0 months $(P<0.001)$ in patients with PVTT involving the main portal vein trunk. Based on another paper, ${ }^{62}$ TACE+RT showed longer OS in selected patients with locally advanced HCC in BCLC stage $C$ who had macrovascular invasion in $96 \%$ of cases and received RT to vascular invasions, compared to sorafenib event after propensity score matching. Tang $\mathrm{QH}$, et al. ${ }^{61}$ also compared the outcomes of surgical resection plus 3D-CRT to tumor and PVTT with resection alone. There was a median survival advantage of 2.3 months $(P=0.03)$, and 1 -year survival rate was $52 \%$. Stereotactic ablative radiotherapy (SABR) (median 40 Gy in 4-5 fractions) using CyberKnife was also suggested as a feasible treatment option. ${ }^{70}$ In a multicenter retrospective study in Korea, ${ }^{67}$ outcomes of 985 patients who received RT for PVTT ( \pm whole HCC) were analyzed, and response rate of PVTT was reported as 52\%. Respond- ers had significantly more prolonged survival (15 vs. 10 months) and equivalent RT dose $>45$ Gy when given in combination with other treatments, and provided significantly better PVTT control and OS.

Recently, meta-analysis results of eight clinical studies regarding this subject were published in China. ${ }^{71}$ TACE+RT significantly improved objective response rate $(\mathrm{OR}, 4.22 ; 95 \% \mathrm{Cl}, 3.07-5.80$; $P<0.001$ ) of PVTT and OS (HR, $0.69 ; 95 \% \mathrm{Cl}, 0.57-0.83 ; P=0.001$ ), compared to TACE alone, although incidence of grade 3 or 4 leukopenia and thrombocytopenia was significantly higher.

\section{Radiotherapy for huge HCC}

RT can be very challenging to perform in some cases of very large unresectable HCCs. Although TACE has been frequently used in treatment of unresectable HCC, its limitation has also been well known, especially in large tumors, particularly regarding complicated blood supply and high incidence of residual viable tumor even after repeated treatment. Although surgical resection could also be tried in some cases, its indication is very limited. Shim SJ, et al. showed that TACE+RT offered more significant benefit than TACE alone when tumor size was larger. ${ }^{37}$ According to the specific tumor size, 2-year survival rates in TACE+RT and TACE groups were $63 \%$ vs. $42 \%$ in $5-7 \mathrm{~cm}(P=0.22), 50 \%$ vs. $0 \%$ in $8-10 \mathrm{~cm}(P=0.03)$, and $17 \%$ vs. $0 \%$ in larger than $10 \mathrm{~cm}(P=0.002)$, respectively. In addition, Kim KH, et al. tried to find the most optimal treatment for huge $\mathrm{HCCs} \geq 10 \mathrm{~cm}$ in patients who received various treatments at the same single institution. ${ }^{72}$ Median OS was longer in TACE+RT group (15.3 months) and concurrent chemoradiotherapy (CCRT) group (12.8 months), compared to TACE alone group (7.5 months) and hepatic arterial infusion chemotherapy (HAIC) alone group (8.2 months); this indicated that huge unresectable HCCs treated with RT, either as CCRT or in combination with TACE, showed excellent intrahepatic control and prolonged survival.

\section{RT for HCC with multiple intrahepatic metastases}

The role of local RT is more uncertain for HCC with multiple intrahepatic metastases. In one retrospective study ${ }^{73}$, local RT to the main tumor was most beneficial with well-controlled intrahepatic tumors out of RT field. Patients with viable intrahepatic tumors out of RT field showed worse survival. Survival was similar when all lesions were covered by RT field, or lesions out of RT field were controlled by TACE. In a more recent study $y^{57}$, TACE for intrahepatic metastases and localized CCRT were given to HCCs with portal vein invasion and intrahepatic metastasis. Objective response rate was 


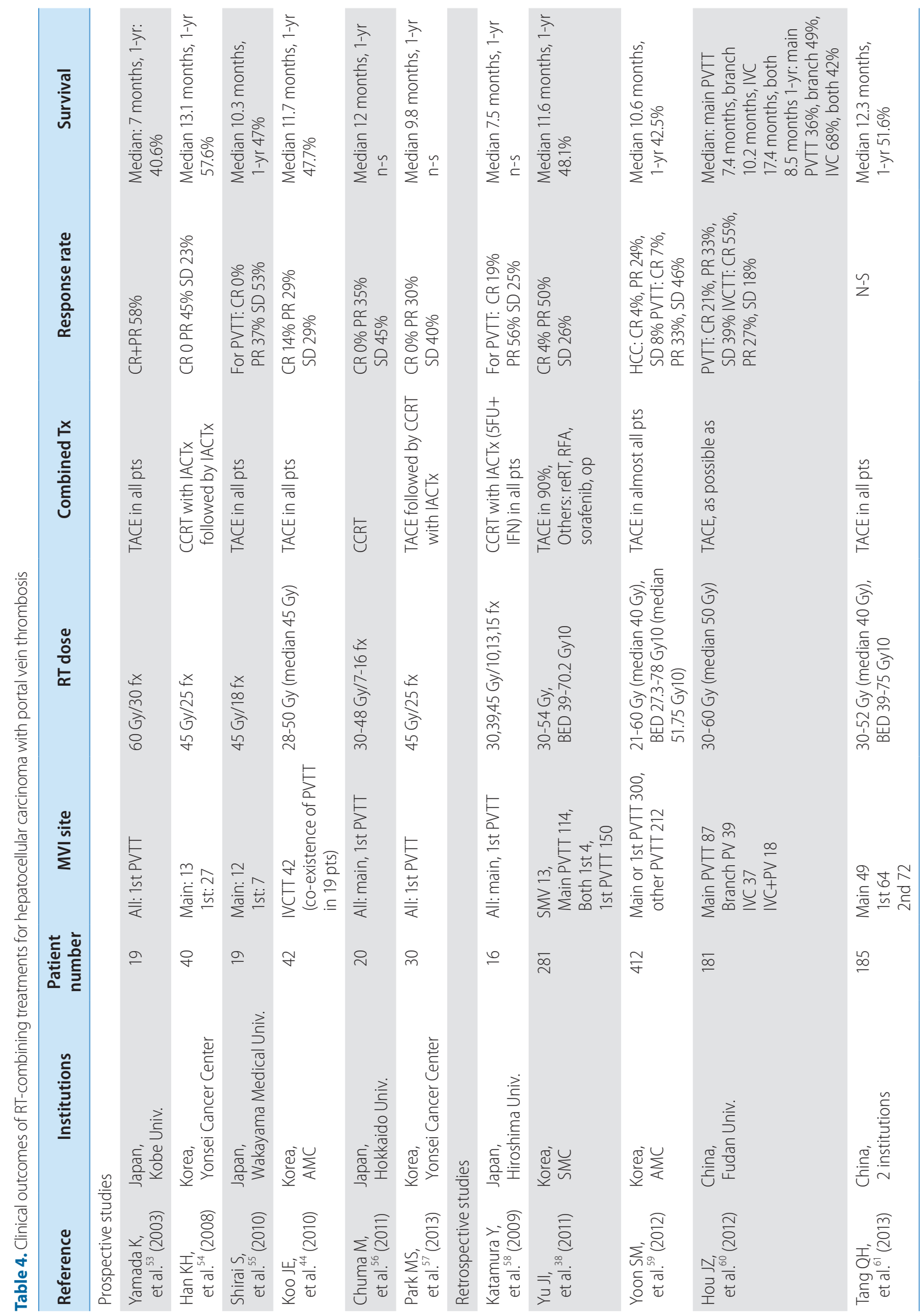


Seo Hee Choi, et al.

Modern RT strategies for HCC

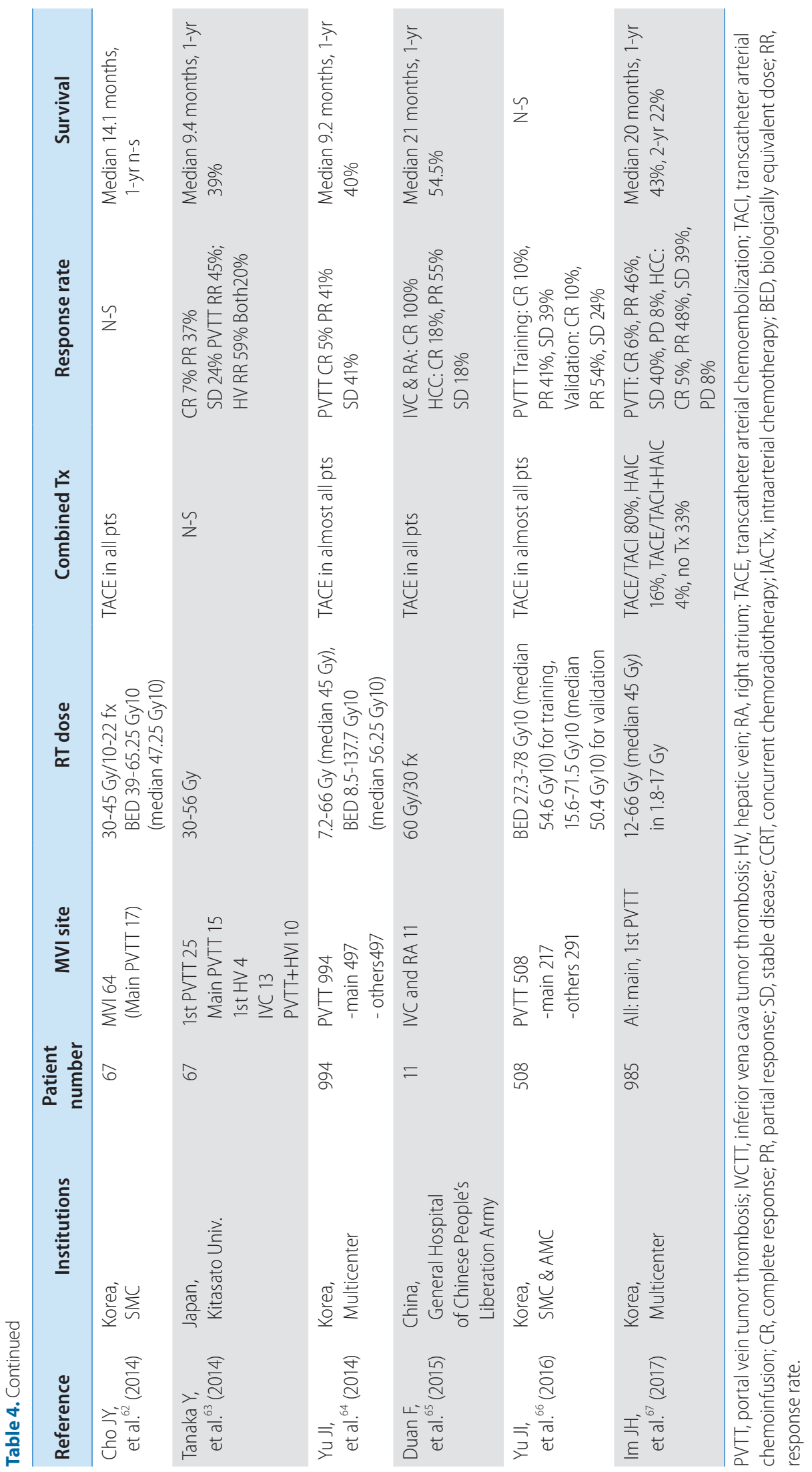


32.1\%, and median PFS and OS were 4.5 months and 9.8 months, respectively. Incidence of grade 3-4 toxicity was low, manageable, and predictable, although two patients dropped out due to grade 3 nausea and vomiting.

\section{Concurrent chemoradiotherapy for advanced stage $\mathrm{HCC}$}

Several studies have indicated that hepatic arterial infusion concurrent chemoradiation (HAICCRT) may be a feasible and effective alternative for unresectable liver-confined HCC with vascular invasion. The purpose of using HAIC in CCRT was to enhance local radio-therapeutic effect and to reduce intrahepatic HCC spread.

One pilot clinical study reported that CCRT improved response rates and survival for locally advanced HCC with portal vein invasion. ${ }^{54}$ One month after localized CCRT, objective response was observed in $45 \%$ of patients, and 3-year survival rate was $24 \%$ which was significantly better compared to non-responders. More recently, the same institution showed treatment outcomes of 30 HCCs with portal vein invasion and intrahepatic metastasis. ${ }^{57}$ After TACE for intrahepatic metastasis, localized CCRT (45 Gy in 25 fractions) was used to treat the main HCC with PVT. Objective response rate was about $30 \%$ and median OS was 9.8 months, without any severe adverse events. Review of nationwide multi-center HCC cohort (stage III-IV, CP-A) showed that patients who underwent definitive CCRT as initial treatment showed significantly better OS (median 11.4 versus 6.6 months, $P=0.02$ ) than matched patients who did not receive CCRT. ${ }^{74}$ CCRT followed by HAIC in locally advanced HCC could even increase resectability by down-staging tumors and increasing functional residual liver volume, and 5-year OS was significantly increased to $50 \%$ (versus $10 \%$ ). ${ }^{75,76}$ In addition, EBRT can significantly relieve symptoms that are caused by locally advanced HCC or metastatic tumors, and even a prolongation of survival period can be expected. ${ }^{77,78}$

\section{DOSE CONSTRAINTS}

Development of improved treatment planning and dose delivery methods, such as 3D-CRT and IMRT, provided a mechanism not only to target hepatic lesions while sparing uninvolved hepatic parenchyma but also to precisely measure radiation dose delivered to both tumor volume and surrounding normal tissue. Despite technical advances, RILD still remains to be a side effect that presents significant concerns when planning RT for HCC.
RILD is a clinical syndrome of anicteric hepatomegaly, ascites, and elevated liver enzymes (particularly serum alkaline phosphatase) that occurs typically 2 weeks to 4 months after completion of hepatic irradiation. Tolerance of the whole liver to radiation is low, and RILD is seen in 5-10\% of patients treated with $30-35$ Gy to the whole liver, based on several Radiation Therapy Oncology Group (RTOG) studies in the 1970's and 1980's. For this reason, radiation has traditionally played a limited role in the treatment of liver tumors. However, treatment of liver parts using higher radiation doses is possible without adverse effects, as long as an adequate volume of normal liver is saved.

While the Emami report established baseline liver tolerance doses based on literature reports of toxicity, ${ }^{79}$ later studies provided more detailed assessment and guidelines regarding the risk of hepatotoxicity for given RT doses. At the University of Michigan, ${ }^{80}$ dose-volume tolerance for RILD using the Lyman-Kutcher-Burman (LKB) normal tissue complication probability (NTCP) model was described. They demonstrated that the liver exhibits a large volume effect for RILD, suggesting that the mean liver dose may be useful in ranking radiation plans. No cases of RILD were observed when the mean liver dose was <31 Gy. Furthermore, multivariate analysis demonstrated that, in addition to NTCP and the mean liver dose, a primary hepatobiliary cancer diagnosis (vs. liver metastases), bromodeoxyuridine hepatic artery chemotherapy (vs. fluorodeoxyuridine chemotherapy), and male gender were associated with RILD. In a preclinical study ${ }^{81}$ that treated rat cirrhosis model with mildly impaired liver function, combined treatment of partial RT plus 5-FU resulted in a significantly high incidence of lethal liver injury. According to Dawson LA's review paper, ${ }^{82}$ if the effective liver volume irradiated is less than $25 \%$, very high RT doses (>100 Gy) may be delivered with little risk of liver toxicity, as long as the liver function is proper. In addition, RT tolerance of the liver is reduced in patients with primary liver cancer versus metastases. The mean liver doses associated with 5\% risk of classic RILD for primary and metastatic liver cancer are $28 \mathrm{~Gy}$ and $32 \mathrm{~Gy}$, respectively, in 2 Gy per fraction.

According to recent papers, ${ }^{83,84}$ there are several dose-volumetric parameters related to the risk of RILD, which are also included in the 2014 KLCSG guidelines. Tumor volume must be limited to $\leq 70 \%$ of the total liver volume, and liver volume receiving $\geq 30 \mathrm{~Gy}$ must be constrained to $\leq 60 \%$ of total liver volume on dose-volume histograms for 3D-RT planning. For SBRT, normal liver volume receiving a total dose of $<15$ Gy must be $\geq 700 \mathrm{~mL}$, or the mean normal liver dose (liver minus gross tumor volume) must be limited to $<28 \mathrm{~Gy}$ in 2-Gy fractions. Although additional studies for liver toler- 
ance to radiation are still needed, several institutions have similarly applied dose-volume histogram parameter-based RT guidelines.

\section{CHARGED PARTICLE THERAPY}

Charged particle therapy (CPT), such as proton and carbon ion therapy, is a form of radiotherapy with superior depth dose distribution compared to photon radiotherapy. This superiority in depth dose distribution is attained by the energy-dependent specific range of charged particles within the tissues and the Bragg peak, which is the sharp peak of energy deposit just before stopping the particle. Consequently, tumors can be treated more efficiently with less toxicity by charged particles than by photons on theoretical grounds, even in the cirrhotic liver with limited hepatic functional reserve. Some retrospective and prospective studies have reported encouraging outcomes with proton or carbon beam therapy in patients with HCC. Local control rates were $88 \%-98 \%$ at 2-5 years, with very low incidence of severe toxicity.

\section{Proton beam therapy}

At the University of Tsukuba, long-term results of proton beam therapy (PBT) for HCCs were reported. ${ }^{85-88}$ A total dose of 77.0 gray-equivalent (GyE) in 35 fractions was administered for tumors located within $2 \mathrm{~cm}$ of a digestive organ, $72.6 \mathrm{GyE}$ in 22 fractions was administered for tumors located within $2 \mathrm{~cm}$ of the porta hepatis, and 66.0 GyE in 10 fractions was administered for peripheral tumors located more than $2 \mathrm{~cm}$ from both $\mathrm{Gl}$ tract and porta hepatis. The 5 -year survival was $23.5 \%$, and local control rate was $86.9 \%$. For a patient subgroup having BCLC stage O/A HCCs, 5 -year local control, PFS, and OS rates were much higher (94\%, $28 \%$, and $69 \%$ ). Otherwise, there were very few acute reactions to treatment, in addition to a few grade 2 or more severe sequelae. So far, the largest prospective study of PBT for HCC was reported by the Loma Linda University Medical Center. ${ }^{89,90}$ After 63 GyE in 15 fractions of PBT, 20\% had experienced local treatment failure, and median PFS was 36 months. No acute toxicity that required treatment interruption was found; however, five cases of grade 2 gastrointestinal bleeding or ulceration near the irradiated area were observed in patients who were treated in earlier period. In another phase II study of MGH, ${ }^{91,92} 67.5$ GyE and 58.05 GyE in 15 fractions for peripheral and central tumors were delivered, and $94 \%$ of favorable 2 -year local control rate was reported. No local recurrence was reported with $\geq 60 \mathrm{GyE}$, and median PFS and OS were 13.9 months and 49.9 months, respectively. In other prospective studies, ${ }^{93-95}$ PBT showed about $95 \%$ of 2-year local control rates and $63-66 \%$ of 2-yr OS rates (Table 5). In a recent interim analysis of prospective randomized clinical trial comparing PBT and $\mathrm{TACE}^{96}$, 2-year local control and PFS rates were higher with PBT ( $88 \%$ vs. $45 \%, 48 \%$ vs. $31 \%$ ), although they were not significantly different. The total number of hospitalization days was significantly shorter in patients with PBT (24 vs. 166 days, $P<0.001$ ). Pathologic complete response was achieved in $10 \%$ of TACE group and $25 \%$ of PBT group, who underwent liver transplantation after treatment. There was a trend toward improved 2-year local control ( $88 \%$ vs. $45 \%, P=0.06)$ and PFS ( $48 \%$ vs. $31 \%, P=0.06)$ favoring PBT.

Excellent local tumor control was reported, even in tumors with portal vein invasion (Table 5). ${ }^{97-99}$ Sugahara $S$, et al. ${ }^{98}$ demonstrated that 2-year PFS and OS rates were $91 \%$ and 33-57\% after PBT for HCC with PVTT, without treatment-related severe complications. Kim, et al. ${ }^{93}$ also treated HCC with PVT, and local recurrence was noted in only $12 \%$ of patients during follow-up period, without local recurrence or severe gastrointestinal toxicity. In addition, proper local control rates can be expected for HCC patients with large tumors ( $87 \%$ at 2 years for tumors $>10 \mathrm{~cm}$ ) or portal tumors (86\% at 3 years), as well as for elderly patients (100\% at 3 years for patients aged $\geq 80$ years). ${ }^{100-103}$ Even for recurrent tumors after PBT, repeated PBT can be safely delivered with an excellent local control rate of $87.8 \%$ at 5 years. ${ }^{104}$

With concerns about gastrointestinal toxicities and hepatic insufficiencies, Kawashima $M$, et al. ${ }^{105}$ analyzed dose-volume histogram of 60 patients with HCC who were treated by PBT, and reported ICG R15 and V30 as useful predictors. According to the location of tumor, a risk-adapted simultaneous integrated boost technique could be utilized to avoid gastrointestinal toxicities. When PTV overlaps the planning organ at risk volume (PRV) of gastrointestinal tract, 50-60 GyE in 10 fractions was prescribed to PTV minus the overlapping volumes, whereas the dose to overlapping volumes was restricted to $30 \mathrm{GyE}$ in 10 fractions. ${ }^{106}$ Mizumoto $\mathrm{M}$, et al. $^{86}$ also suggested risk-adapted selection scheme dose fractionation schedules. They adopted a small fraction dose schedule of 77 GyE in 35 fractions with gastrointestinal tract avoidance as far as possible, after 40-50 GyE for tumors proximal to the alimentary tract with reduced risk of gastrointestinal toxicities.

\section{Carbon ion beam therapy}

Although it is expected that the biological benefits of high rela- 


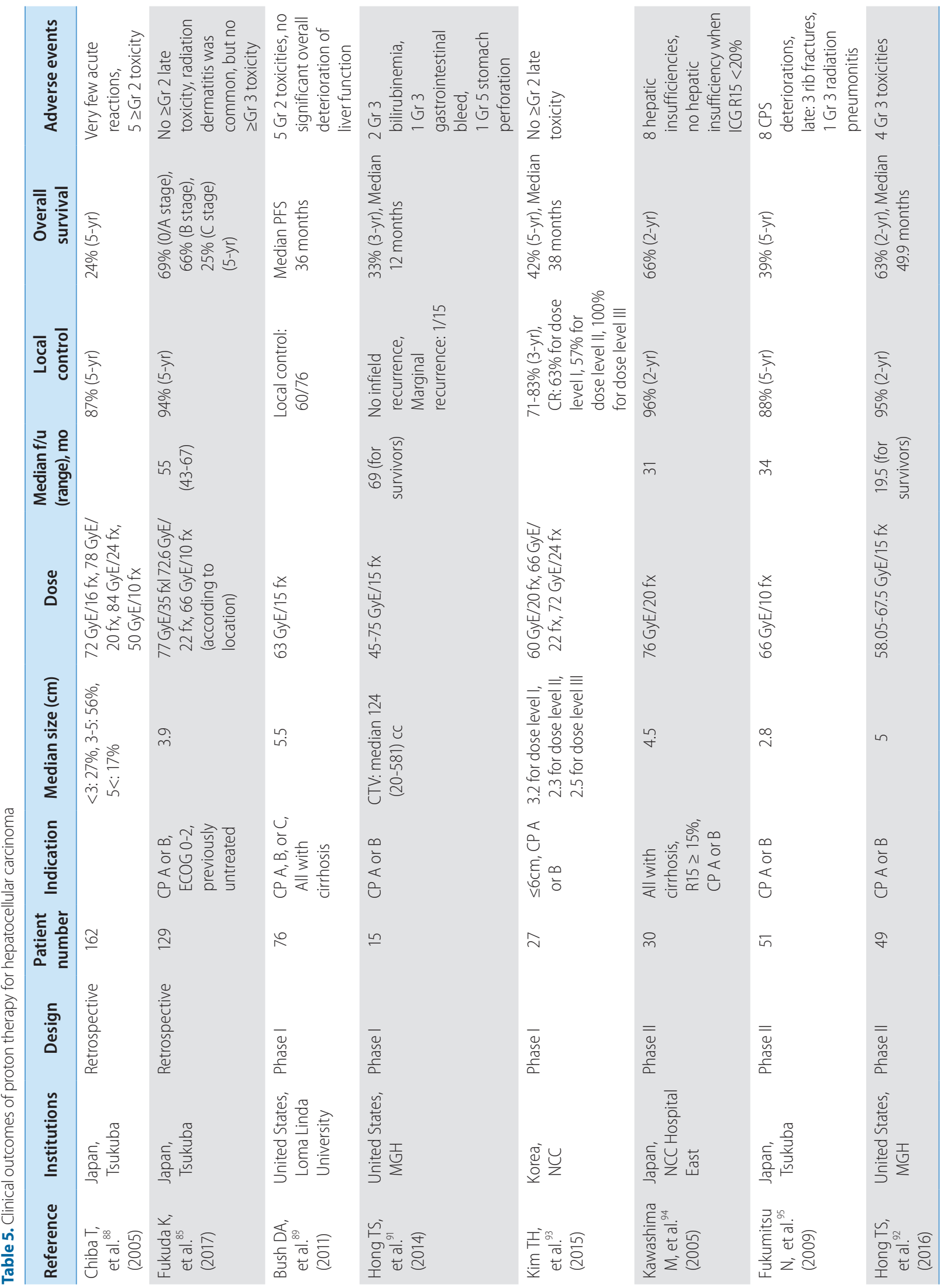




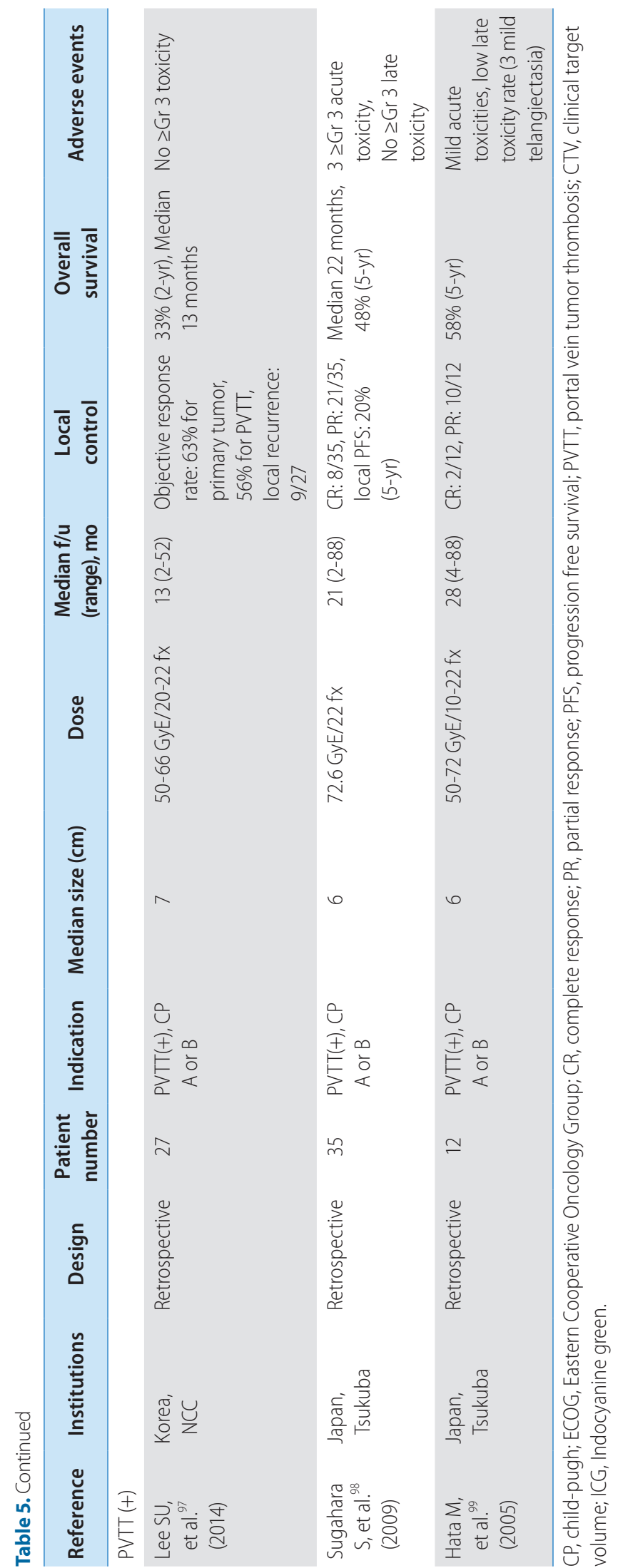

tive biological effectiveness (RBE) and high linear energy transfer (LET) of carbon ion beam would offer better treatment efficacy than photon or PBT, clinical experience for carbon ion beam is not yet extensive.

The first clinical result of carbon ion therapy for HCC was published by the NIRS in 2004. ${ }^{107}$ In 24 patients who were enrolled in this study and received 49.5 GyE-79.5 GyE in 15 fractions, 3-year local control and OS rates were $81 \%$ and $50 \%$, respectively. The OS rates of patients who had not received previous treatment for HCC were significantly higher than those who did. In particular, there was no local recurrence in patients receiving more than $72 \mathrm{GyE}$, and severe adverse events were not reported at any dose level. To date, NIRS researchers have conducted several other clinical trials for $\mathrm{HCC}$ with short-course irradiation regimens. A four-fraction regimen, with a total dose of $52.8 \mathrm{GyE}$, also yielded a high local control rate of $94 \%$ at 3 years. ${ }^{108}$ Although local control rates for porta hepatis lesions were slightly worse than those for non-porta hepatis lesions, the difference was not statistically significant ( 88 vs. $96 \%, P=0.306$ ). ${ }^{109}$ Two-fraction regimens are now being adopted with minor adverse events only, ${ }_{1}{ }^{110}$ and follow-up clinical data is not yet available. Other hypofractionated regimens with dose escalation have been also studied, and mature data will be reported in the near future.

Komatsu S, et al. compared the clinical outcomes of PBT (278 tumors) to carbon ion therapy (108 tumors) in patients who were treated at the same institution. ${ }^{111}$ The 5 -year local control rates for PBT and carbon ion were $90 \%$ and $93 \%$, respectively. For tumors $<5 \mathrm{~cm}$, local control rates were similar between two modalities (96\% vs. $95 \%)$; however, the rates were slightly lower with PBT than carbon ion therapy for larger tumors ( $84 \%$ vs. $91 \%$ for tumors of $5-10 \mathrm{~cm}$; $43 \%$ vs. $80 \%$ for tumors $>10 \mathrm{~cm}$ ). In meta-analysis of 70 non-comparative observational studies ( 73 cohorts; 53 with photon therapy, and 20 with $(\mathrm{CPT})^{112}$, the median radiation dose was higher in CPT cohorts compared to SBRT and conventional RT cohorts, while the median rate of patients with child-pugh A class was higher in CRT cohorts than in other cohorts. Additionally, median tumor size, rate of male, rate of patients with ECOG PS 0-1, or median HCC patients with tumor vascular thrombosis did not significantly differ between groups. The OS, PFS, and local control rates were significantly higher for CPT than those for conventional RT, while they were similar to SBRT in patients with HCC. Furthermore, high-grade acute and late toxicities were lower for CPT compared to conventional RT or SBRT. 
So far, CPT generally showed better local control and survival rates than photon-based RT series, although a direct comparison is difficult due to differences in patient characteristics. Although facilities for CPT have been limited to this day, the use of CPT is anticipated to increase in the near future.

\section{Author contribution}

SH Choi and J Seong contributed to this paper with conception and design of the study, literature review and analysis, drafting and critical revision and editing, and final approval of the final version.

\section{Conflicts of Interest}

The authors have no conflicts to disclose.

\section{REFERENCES}

1. Benson AB, 3rd, D'Angelica MI, Abbott DE, Abrams TA, Alberts SR, Saenz DA, et al. NCCN Guidelines Insights: Hepatobiliary Cancers, Version 1.2017. J Natl Compr Canc Netw 2017;15:563-573.

2. Korean Liver Cancer Study Group, National Cancer Center Korea. 2014 KLCSG-NCC Korea Practice Guideline for the Management of Hepatocellular Carcinoma. Gut Liver 2015;9:267-317.

3. Louis C, Dewas S, Mirabel X, Lacornerie T, Adenis A, Bonodeau F, et al. Stereotactic radiotherapy of hepatocellular carcinoma: preliminary results. Technol Cancer Res Treat 2010;9:479-487.

4. Huang WY, Jen YM, Lee MS, Chang LP, Chen CM, Ko KH, et al. Stereotactic body radiation therapy in recurrent hepatocellular carcinoma. Int J Radiat Oncol Biol Phys 2012;84:355-361.

5. Goyal K, Einstein D, Yao M, Kunos C, Barton F, Singh D, et al. Cyberknife stereotactic body radiation therapy for nonresectable tumors of the liver: preliminary results. HPB Surg 2010;2010.

6. Que J, Kuo HT, Lin LC, Lin KL, Lin CH, Lin YW, et al. Clinical outcomes and prognostic factors of cyberknife stereotactic body radiation therapy for unresectable hepatocellular carcinoma. BMC Cancer 2016;16:451.

7. Liang P, Huang C, Liang SX, Li YF, Huang SX, Lian ZP, et al. Effect of CyberKnife stereotactic body radiation therapy for hepatocellular carcinoma on hepatic toxicity. Onco Targets Ther 2016;9:7169-7175.

8. Herfarth KK, Debus J, Lohr F, Bahner ML, Rhein B, Fritz P, et al. Stereotactic single-dose radiation therapy of liver tumors: results of a phase I/II trial. J Clin Oncol 2001;19:164-170.

9. Tse RV, Hawkins M, Lockwood G, Kim JJ, Cummings B, Knox J, et al. Phase I study of individualized stereotactic body radiotherapy for hepatocellular carcinoma and intrahepatic cholangiocarcinoma. J Clin Oncol 2008;26:657-664.
10. Wulf J, Guckenberger M, Haedinger U, Oppitz U, Mueller G, Baier K, et al. Stereotactic radiotherapy of primary liver cancer and hepatic metastases. Acta Oncol 2006;45:838-847.

11. Goodman KA, Wiegner EA, Maturen KE, Zhang Z, Mo Q, Yang G, et al. Dose-escalation study of single-fraction stereotactic body radiotherapy for liver malignancies. Int J Radiat Oncol Biol Phys 2010;78:486-493.

12. Cárdenes HR, Price TR, Perkins SM, Maluccio M, Kwo P, Breen TE, et al. Phase I feasibility trial of stereotactic body radiation therapy for primary hepatocellular carcinoma. Clin Transl Oncol 2010;12:218 225.

13. Andolino DL, Johnson CS, Maluccio M, Kwo P, Tector AJ, Zook J, et al. Stereotactic body radiotherapy for primary hepatocellular carcinoma. Int J Radiat Oncol Biol Phys 2011;81:e447-e453.

14. Price TR, Perkins SM, Sandrasegaran K, Henderson MA, Maluccio MA, Zook JE, et al. Evaluation of response after stereotactic body radiotherapy for hepatocellular carcinoma. Cancer 2012;118:3191-3198.

15. Kang JK, Kim MS, Cho CK, Yang KM, Yoo HJ, Kim JH, et al. Stereotactic body radiation therapy for inoperable hepatocellular carcinoma as a local salvage treatment after incomplete transarterial chemoembolization. Cancer 2012;118:5424-5431.

16. Bujold A, Massey CA, Kim JJ, Brierley J, Cho C, Wong RK, et al. Sequential phase I and II trials of stereotactic body radiotherapy for locally advanced hepatocellular carcinoma. J Clin Oncol 2013;31:1631 1639.

17. Kim JW, Seong J, Lee IJ, Woo JY, Han KH. Phase I dose escalation study of helical intensity-modulated radiotherapy-based stereotactic body radiotherapy for hepatocellular carcinoma. Oncotarget 2016;7:40756-40766.

18. Choi BO, Jang HS, Kang KM, Lee SW, Kang YN, Chai GY, et al. Fractionated stereotactic radiotherapy in patients with primary hepatocellular carcinoma. Jpn J Clin Oncol 2006;36:154-158.

19. Choi BO, Choi IB, Jang HS, Kang YN, Jang JS, Bae SH, et al. Stereotactic body radiation therapy with or without transarterial chemoembolization for patients with primary hepatocellular carcinoma: preliminary analysis. BMC Cancer 2008;8:351.

20. Kwon JH, Bae SH, Kim JY, Choi BO, Jang HS, Jang JW, et al. Longterm effect of stereotactic body radiation therapy for primary hepatocellular carcinoma ineligible for local ablation therapy or surgical resection. Stereotactic radiotherapy for liver cancer. BMC Cancer 2010;10:475.

21. Seo YS, Kim MS, Yoo SY, Cho CK, Choi CW, Kim JH, et al. Preliminary result of stereotactic body radiotherapy as a local salvage treatment for inoperable hepatocellular carcinoma. J Surg Oncol 2010;102:209214.

22. Honda Y, Kimura T, Aikata H, Kobayashi T, Fukuhara T, Masaki K, et al. Stereotactic body radiation therapy combined with transcatheter arterial chemoembolization for small hepatocellular carcinoma. J 
Gastroenterol Hepatol 2013;28:530-536.

23.Xi M, Zhang L, Zhao L, Li QQ, Guo SP, Feng ZZ, et al. Effectiveness of stereotactic body radiotherapy for hepatocellular carcinoma with portal vein and/or inferior vena cava tumor thrombosis. PLoS One 2013;8:e63864.

24. Jang WI, Kim MS, Bae SH, Cho CK, Yoo HJ, Seo YS, et al. High-dose stereotactic body radiotherapy correlates increased local control and overall survival in patients with inoperable hepatocellular carcinoma. Radiat Oncol 2013;8:250.

25. Sanuki N, Takeda A, Oku Y, Mizuno T, Aoki Y, Eriguchi T, et al. Stereotactic body radiotherapy for small hepatocellular carcinoma: a retrospective outcome analysis in 185 patients. Acta Oncol 2014;53:399404.

26. Culleton S, Jiang H, Haddad CR, Kim J, Brierley J, Brade A, et al. Outcomes following definitive stereotactic body radiotherapy for patients with Child-Pugh B or C hepatocellular carcinoma. Radiother Oncol 2014;111:412-417.

27. Bae SH, Kim MS, Cho CK, Kim KB, Lee DH, Han CJ, et al. Feasibility and efficacy of stereotactic ablative radiotherapy for Barcelona Clinic Liver Cancer-C stage hepatocellular carcinoma. J Korean Med Sci 2013;28:213-219.

28. Que JY, Lin LC, Lin KL, Lin CH, Lin YW, Yang CC. The efficacy of stereotactic body radiation therapy on huge hepatocellular carcinoma unsuitable for other local modalities. Radiat Oncol 2014;9:120.

29.Zhong NB, Lv GM, Chen ZH. Stereotactic body radiotherapy combined with transarterial chemoembolization for huge $(\geq 10 \mathrm{~cm})$ hepatocellular carcinomas: a clinical study. Mol Clin Oncol 2014;2:839844.

30. Wahl DR, Stenmark MH, Tao Y, Pollom EL, Caoili EM, Lawrence TS, et al. Outcomes After Stereotactic Body Radiotherapy or Radiofrequency Ablation for Hepatocellular Carcinoma. J Clin Oncol 2016;34:452459.

31. O'Connor JK, Trotter J, Davis GL, Dempster J, Klintmalm GB, Goldstein RM. Long-term outcomes of stereotactic body radiation therapy in the treatment of hepatocellular cancer as a bridge to transplantation. Liver Transpl 2012;18:949-954.

32. Sapisochin G, Barry A, Doherty M, Fischer S, Goldaracena N, Rosales $R$, et al. Stereotactic body radiotherapy vs. TACE or RFA as a bridge to transplant in patients with hepatocellular carcinoma. An intention-to-treat analysis. J Hepatol 2017;67:92-99.

33. Lee CS, Sung JL, Hwang LY, Sheu JC, Chen DS, Lin TY, et al. Surgical treatment of 109 patients with symptomatic and asymptomatic hepatocellular carcinoma. Surgery 1986;99:481-490.

34. Trevisani F, De Notariis S, Rossi C, Bernardi M. Randomized control trials on chemoembolization for hepatocellular carcinoma: is there room for new studies? J Clin Gastroenterol 2001;32:383-389.

35. Geschwind JF, Ramsey DE, Choti MA, Thuluvath PJ, Huncharek MS. Chemoembolization of hepatocellular carcinoma: results of a meta- analysis. Am J Clin Oncol 2003;26:344-349.

36.Zeng ZC, Tang ZY, Fan J, Zhou J, Qin LX, Ye SL, et al. A comparison of chemoembolization combination with and without radiotherapy for unresectable hepatocellular carcinoma. Cancer J 2004;10:307316.

37. Shim SJ, Seong J, Han KH, Chon CY, Suh CO, Lee JT. Local radiotherapy as a complement to incomplete transcatheter arterial chemoembolization in locally advanced hepatocellular carcinoma. Liver Int 2005;25:1189-1196.

38. Yu Jl, Park HC, Lim DH, Park W, Yoo BC, Paik SW, et al. Prognostic index for portal vein tumor thrombosis in patients with hepatocellular carcinoma treated with radiation therapy. J Korean Med Sci 2011;26:1014-1022.

39. Guo WJ, Yu EX. Evaluation of combined therapy with chemoembolization and irradiation for large hepatocellular carcinoma. Br J Radiol 2000;73:1091-1097.

40. Li B, Yu J, Wang L, Li C, Zhou T, Zhai L, et al. Study of local threedimensional conformal radiotherapy combined with transcatheter arterial chemoembolization for patients with stage III hepatocellular carcinoma. Am J Clin Oncol 2003;26:e92-e99.

41. Oh D, Lim DH, Park HC, Paik SW, Koh KC, Lee JH, et al. Early threedimensional conformal radiotherapy for patients with unresectable hepatocellular carcinoma after incomplete transcatheter arterial chemoembolization: a prospective evaluation of efficacy and toxicity. Am J Clin Oncol 2010;33:370-375.

42. Leng ZQ, Liang ZY, Shi S, Hu ZX. Comparison of treatment results of interventional therapy alone, radiotherapy alone, and combined interventional therapy plus radiotherapy for primary hepatic cancer. Chin J Radiat Oncol 2000;9:99-101.

43.Zhao MH, Lang FP, Jiang QA, Ma JJ, Song YX. Three-dimensional conformal radiotherapy combined with transcatheter arterial chemoembolization for inoperable primary liver cancer. Chin J Radiat Oncol 2006;15:39-41.

44. Koo JE, Kim JH, Lim YS, Park SJ, Won HJ, Sung KB, et al. Combination of transarterial chemoembolization and three-dimensional conformal radiotherapy for hepatocellular carcinoma with inferior vena cava tumor thrombus. Int J Radiat Oncol Biol Phys 2010;78:180-187.

45. Choi C, Koom WS, Kim TH, Yoon SM, Kim JH, Lee HS, et al. A prospective phase 2 multicenter study for the efficacy of radiation therapy following incomplete transarterial chemoembolization in unresectable hepatocellular carcinoma. Int J Radiat Oncol Biol Phys 2014;90:1051-1060.

46. Cheng JC, Chuang VP, Cheng SH, Huang AT, Lin YM, Cheng TI, et al. Local radiotherapy with or without transcatheter arterial chemoembolization for patients with unresectable hepatocellular carcinoma. Int J Radiat Oncol Biol Phys 2000;47:435-442.

47. Guo WJ, Yu EX. Large primary liver cancer treated by chemoembolization combined with radiotherapy successfully. Hepatogastroenter- 
ology 2003;50:519-522

48.Li Y, Yan Y, Zhang HB, Guo ZW, Yan ZC, Li D. Three-dimensional conformal radiation combined with transarterial chemoembolization for unresectable primary liver cancer. Chin J Radiat Oncol 2003;12:30-32.

49. Chen WJ, Yuan SF, Zhu LJ, Sun XN, Zheng W. Three-dimensional conformal radiotherapy in combination with transcatheter arterial chemoembolization in the treatment of hepatocellular carcinoma. J BUON 2014;19:692-697.

50. Meng MB, Cui YL, Lu Y, She B, Chen Y, Guan YS, et al. Transcatheter arterial chemoembolization in combination with radiotherapy for unresectable hepatocellular carcinoma: a systematic review and meta-analysis. Radiother Oncol 2009;92:184-194.

51. Liao M, Huang J, Zhang T, Wu H. Transarterial chemoembolization in combination with local therapies for hepatocellular carcinoma: a meta-analysis. PLoS One 2013;8:e68453.

52. Huo YR, Eslick GD. Transcatheter Arterial Chemoembolization Plus Radiotherapy Compared With Chemoembolization Alone for Hepatocellular Carcinoma: A Systematic Review and Meta-analysis. JAMA Oncol 2015;1:756-765.

53. Yamada K, Izaki K, Sugimoto K, Mayahara H, Morita Y, Yoden E, et al. Prospective trial of combined transcatheter arterial chemoembolization and three-dimensional conformal radiotherapy for portal vein tumor thrombus in patients with unresectable hepatocellular carcinoma. Int J Radiat Oncol Biol Phys 2003;57:113-119.

54. Han KH, Seong J, Kim JK, Ahn SH, Lee DY, Chon CY. Pilot clinical trial of localized concurrent chemoradiation therapy for locally advanced hepatocellular carcinoma with portal vein thrombosis. Cancer 2008;113:995-1003.

55. Shirai S, Sato M, Suwa K, Kishi K, Shimono C, Sonomura T, et al. Feasibility and efficacy of single photon emission computed tomographybased three-dimensional conformal radiotherapy for hepatocellular carcinoma $8 \mathrm{~cm}$ or more with portal vein tumor thrombus in combination with transcatheter arterial chemoembolization. Int J Radiat Oncol Biol Phys 2010;76:1037-1044.

56. Chuma M, Taguchi H, Yamamoto Y, Shimizu S, Nakanishi M, Ogawa $K$, et al. Efficacy of therapy for advanced hepatocellular carcinoma: intra-arterial 5-fluorouracil and subcutaneous interferon with imageguided radiation. J Gastroenterol Hepatol 2011;26:1123-1132.

57. Park MS, Kim SU, Park JY, Kim DY, Ahn SH, Han KH, et al. Combination treatment of localized concurrent chemoradiation therapy and transarterial chemoembolization in locally advanced hepatocellular carcinoma with intrahepatic metastasis. Cancer Chemother Pharmacol 2013;71:165-173.

58. Katamura Y, Aikata H, Takaki S, Azakami T, Kawaoka T, Waki K, et al. Intra-arterial 5-fluorouracil/interferon combination therapy for advanced hepatocellular carcinoma with or without three-dimensional conformal radiotherapy for portal vein tumor thrombosis. J Gastro- enterol 2009;44:492-502.

59. Yoon SM, Lim YS, Won HJ, Kim JH, Kim KM, Lee HC, et al. Radiotherapy plus transarterial chemoembolization for hepatocellular carcinoma invading the portal vein: long-term patient outcomes. Int J Radiat Oncol Biol Phys 2012;82:2004-2011.

60. Hou JZ, Zeng ZC, Zhang JY, Fan J, Zhou J, Zeng MS. Influence of tumor thrombus location on the outcome of external-beam radiation therapy in advanced hepatocellular carcinoma with macrovascular invasion. Int J Radiat Oncol Biol Phys 2012;84:362-368.

61. Tang QH, Li AJ, Yang GM, Lai EC, Zhou WP, Jiang ZH, et al. Surgical resection versus conformal radiotherapy combined with TACE for resectable hepatocellular carcinoma with portal vein tumor thrombus: a comparative study. World J Surg 2013;37:1362-1370.

62. Cho JY, Paik YH, Park HC, Yu JI, Sohn W, Gwak GY, et al. The feasibility of combined transcatheter arterial chemoembolization and radiotherapy for advanced hepatocellular carcinoma. Liver Int 2014;34:795-801.

63. Tanaka Y, Nakazawa T, Komori S, Hidaka H, Okuwaki Y, Takada J, et al. Radiotherapy for patients with unresectable advanced hepatocellular carcinoma with invasion to intrahepatic large vessels: efficacy and outcomes. J Gastroenterol Hepatol 2014;29:352-357.

64. Yu JI, Yoon SM, Park HC, Kim JH, Kim TH, Park JW, et al. Multicenter validation study of a prognostic index for portal vein tumor thrombosis in hepatocellular carcinoma. Cancer Res Treat 2014;46:348357.

65. Duan F, Yu W, Wang Y, Liu FY, Song P, Wang ZJ, et al. Trans-arterial chemoembolization and external beam radiation therapy for treatment of hepatocellular carcinoma with a tumor thrombus in the inferior vena cava and right atrium. Cancer Imaging 2015;15:7.

66. Yu JI, Park HC. Radiotherapy as valid modality for hepatocellular carcinoma with portal vein tumor thrombosis. World J Gastroenterol 2016;22:6851-6863.

67. Im JH, Yoon SM, Park HC, Kim JH, Yu JI, Kim TH, et al. Radiotherapeutic strategies for hepatocellular carcinoma with portal vein tumour thrombosis in a hepatitis B endemic area. Liver Int 2017;37:90-100.

68. Kim KM, Kim JH, Park IS, Ko GY, Yoon HK, Sung KB, et al. Reappraisal of repeated transarterial chemoembolization in the treatment of hepatocellular carcinoma with portal vein invasion. J Gastroenterol Hepatol 2009;24:806-814.

69. Li XL, Guo WX, Hong XD, Yang L, Wang K, Shi J, et al. Efficacy of the treatment of transarterial chemoembolization combined with radiotherapy for hepatocellular carcinoma with portal vein tumor thrombus: A propensity score analysis. Hepatol Res 2016;46:1088-1098.

70. Lo CH, Huang WY, Lee MS, Lin KT, Lin TP, Chang PY, et al. Stereotactic ablative radiotherapy for unresectable hepatocellular carcinoma patients who failed or were unsuitable for transarterial chemoembolization. Eur J Gastroenterol Hepatol 2014;26:345-352.

71. Zhao Q, Zhu K, Yue J, Qi Z, Jiang S, Xu X, et al. Comparison of intra- 
arterial chemoembolization with and without radiotherapy for advanced hepatocellular carcinoma with portal vein tumor thrombosis: a meta-analysis. Ther Clin Risk Manag 2017;13:21-31.

72. Kim KH, Kim MS, Chang JS, Han KH, Kim DY, Seong J. Therapeutic benefit of radiotherapy in huge $(\geq 10 \mathrm{~cm})$ unresectable hepatocellular carcinoma. Liver Int 2014;34:784-794.

73. Koom WS, Seong J, Han KH, Lee DY, Lee JT. Is local radiotherapy still valuable for patients with multiple intrahepatic hepatocellular carcinomas? Int J Radiat Oncol Biol Phys 2010;77:1433-1440.

74. Yoon HI, Song KJ, Lee IJ, Kim DY, Han KH, Seong J. Clinical Benefit of Hepatic Arterial Infusion Concurrent Chemoradiotherapy in Locally Advanced Hepatocellular Carcinoma: A Propensity Score Matching Analysis. Cancer Res Treat 2016;48:190-197.

75. Lee HS, Choi GH, Choi JS, Kim KS, Han KH, Seong J, et al. Surgical resection after down-staging of locally advanced hepatocellular carcinoma by localized concurrent chemoradiotherapy. Ann Surg Oncol 2014;21:3646-3653.

76. Lee IJ, Kim JW, Han KH, Kim JK, Kim KS, Choi JS, et al. Concurrent chemoradiotherapy shows long-term survival after conversion from locally advanced to resectable hepatocellular carcinoma. Yonsei Med J 2014;55:1489-1497.

77. Cheng SH, Lin YM, Chuang VP, Yang PS, Cheng JC, Huang AT, et al. A pilot study of three-dimensional conformal radiotherapy in unresectable hepatocellular carcinoma. J Gastroenterol Hepatol 1999;14:1025-1033.

78. Huang JF, Wang LY, Lin ZY, Chen SC, Hsieh MY, Chuang WL, et al. Incidence and clinical outcome of icteric type hepatocellular carcinoma. J Gastroenterol Hepatol 2002;17:190-195.

79. Emami B, Lyman J, Brown A, Coia L, Goitein M, Munzenrider JE, et al. Tolerance of normal tissue to therapeutic irradiation. Int J Radiat Oncol Biol Phys 1991;21:109-122.

80. Dawson LA, Normolle D, Balter JM, McGinn CJ, Lawrence TS, Ten Haken RK. Analysis of radiation-induced liver disease using the Lyman NTCP model. Int J Radiat Oncol Biol Phys 2002;53:810-821.

81. Seong J, Han KH, Park YN, Nam SH, Kim SH, Keum WS, et al. Lethal hepatic injury by combined treatment of radiation plus chemotherapy in rats with thioacetamide-induced liver cirrhosis. Int J Radiat Oncol Biol Phys 2003;57:282-288.

82. Dawson LA, Ten Haken RK. Partial volume tolerance of the liver to radiation. Semin Radiat Oncol 2005;15:279-283.

83. Kim TH, Kim DY, Park JW, Kim SH, Choi JI, Kim HB, et al. Dose-volumetric parameters predicting radiation-induced hepatic toxicity in unresectable hepatocellular carcinoma patients treated with threedimensional conformal radiotherapy. Int J Radiat Oncol Biol Phys 2007:67:225-231.

84.Pan CC, Kavanagh BD, Dawson LA, Li XA, Das SK, Miften M, et al. Radiation-associated liver injury. Int J Radiat Oncol Biol Phys 2010;76(3 Suppl):S94-S100.
85. Fukuda K, Okumura T, Abei M, Fukumitsu N, Ishige K, Mizumoto $M$, et al. Long-term outcomes of proton beam therapy in patients with previously untreated hepatocellular carcinoma. Cancer Sci 2017; 108:497-503.

86. Mizumoto $\mathrm{M}$, Okumura T, Hashimoto T, Fukuda K, Oshiro Y, Fukumitsu N, et al. Proton beam therapy for hepatocellular carcinoma: a comparison of three treatment protocols. Int J Radiat Oncol Biol Phys 2011;81:1039-1045.

87. Nakayama H, Sugahara S, Tokita M, Fukuda K, Mizumoto M, Abei M, et al. Proton beam therapy for hepatocellular carcinoma: the University of Tsukuba experience. Cancer 2009;115:5499-5506.

88. Chiba T, Tokuuye K, Matsuzaki Y, Sugahara S, Chuganji Y, Kagei K, et al. Proton beam therapy for hepatocellular carcinoma: a retrospective review of 162 patients. Clin Cancer Res 2005;11:3799-3805.

89. Bush DA, Kayali Z, Grove R, Slater JD. The safety and efficacy of highdose proton beam radiotherapy for hepatocellular carcinoma: a phase 2 prospective trial. Cancer 2011;117:3053-3059.

90. Bush DA, Hillebrand DJ, Slater JM, Slater JD. High-dose proton beam radiotherapy of hepatocellular carcinoma: preliminary results of a phase II trial. Gastroenterology 2004;127(5 Suppl 1):S189-S193.

91. Hong TS, DeLaney TF, Mamon HJ, Willett CG, Yeap BY, Niemierko $A$, et al. A prospective feasibility study of respiratory-gated proton beam therapy for liver tumors. Pract Radiat Oncol 2014;4:316-322.

92. Hong TS, Wo JY, Yeap BY, Ben-Josef E, McDonnell El, Blaszkowsky LS, et al. Multi-Institutional Phase II Study of High-Dose Hypofractionated Proton Beam Therapy in Patients With Localized, Unresectable Hepatocellular Carcinoma and Intrahepatic Cholangiocarcinoma. J Clin Oncol 2016;34:460-468.

93. Kim TH, Park JW, Kim YJ, Kim BH, Woo SM, Moon SH, et al. Phase I dose-escalation study of proton beam therapy for inoperable hepatocellular carcinoma. Cancer Res Treat 2015;47:34-45.

94. Kawashima M, Furuse J, Nishio T, Konishi M, Ishii H, Kinoshita T, et al. Phase II study of radiotherapy employing proton beam for hepatocellular carcinoma. J Clin Oncol 2005;23:1839-1846.

95. Fukumitsu N, Sugahara S, Nakayama H, Fukuda K, Mizumoto M, Abei $\mathrm{M}$, et al. A prospective study of hypofractionated proton beam therapy for patients with hepatocellular carcinoma. Int J Radiat Oncol Biol Phys 2009;74:831-836.

96. Bush DA, Smith JC, Slater JD, Volk ML, Reeves ME, Cheng J, et al. Randomized Clinical Trial Comparing Proton Beam Radiation Therapy with Transarterial Chemoembolization for Hepatocellular Carcinoma: Results of an Interim Analysis. Int J Radiat Oncol Biol Phys 2016:95:477-482.

97. Lee SU, Park JW, Kim TH, Kim YJ, Woo SM, Koh YH, et al. Effectiveness and safety of proton beam therapy for advanced hepatocellular carcinoma with portal vein tumor thrombosis. Strahlenther Onkol 2014;190:806-814.

98. Sugahara S, Nakayama H, Fukuda K, Mizumoto M, Tokita M, Abei 
$M$, et al. Proton-beam therapy for hepatocellular carcinoma associated with portal vein tumor thrombosis. Strahlenther Onkol 2009;185:782-788

99. Hata M, Tokuuye K, Sugahara S, Kagei K, Igaki H, Hashimoto T, et al. Proton beam therapy for hepatocellular carcinoma with portal vein tumor thrombus. Cancer 2005;104:794-801.

100. Hata M, Tokuuye K, Sugahara S, Tohno E, Nakayama H, Fukumitsu N, et al. Proton beam therapy for aged patients with hepatocellular carcinoma. Int J Radiat Oncol Biol Phys 2007;69:805-812.

101. Mizumoto M, Tokuuye K, Sugahara S, Nakayama H, Fukumitsu N, Ohara K, et al. Proton beam therapy for hepatocellular carcinoma adjacent to the porta hepatis. Int J Radiat Oncol Biol Phys 2008;71:462-467.

102. Sugahara S, Oshiro Y, Nakayama H, Fukuda K, Mizumoto M, Abei M, et al. Proton beam therapy for large hepatocellular carcinoma. Int J Radiat Oncol Biol Phys 2010;76:460-466.

103. Shiba S, Abe T, Shibuya K, Katoh H, Koyama Y, Shimada H, et al. Carbon ion radiotherapy for 80 years or older patients with hepatocellular carcinoma. BMC Cancer 2017;17:721.

104. Hashimoto T, Tokuuye K, Fukumitsu N, Igaki H, Hata M, Kagei K, et al. Repeated proton beam therapy for hepatocellular carcinoma. Int J Radiat Oncol Biol Phys 2006;65:196-202.

105. Kawashima M, Kohno R, Nakachi K, Nishio T, Mitsunaga S, Ikeda M, et al. Dose-volume histogram analysis of the safety of proton beam therapy for unresectable hepatocellular carcinoma. Int J Radiat Oncol Biol Phys 2011;79:1479-1486.
106. Kim DY, Park JW, Kim TH, Kim BH, Moon SH, Kim SS, et al. Riskadapted simultaneous integrated boost-proton beam therapy (SIBPBT) for advanced hepatocellular carcinoma with tumour vascular thrombosis. Radiother Oncol 2017;122:122-129.

107. Kato H, Tsujii H, Miyamoto T, Mizoe JE, Kamada T, Tsuji H, et al. Results of the first prospective study of carbon ion radiotherapy for hepatocellular carcinoma with liver cirrhosis. Int J Radiat Oncol Biol Phys 2004;59:1468-1476.

108. Tsujii H, Mizoe J, Kamada T, Baba M, Tsuji H, Kato H, et al. Clinical Results of Carbon Ion Radiotherapy at NIRS. J Radiat Res 2007;48 Suppl A:A1A13.

109. Imada H, Kato H, Yasuda S, Yamada S, Yanagi T, Kishimoto R, et al. Comparison of efficacy and toxicity of short-course carbon ion radiotherapy for hepatocellular carcinoma depending on their proximity to the porta hepatis. Radiother Oncol 2010;96:231-235.

110. Kamada T, Tsujii H, Blakely EA, Debus J, De Neve W, Durante M, et al. Carbon ion radiotherapy in Japan: an assessment of 20 years of clinical experience. Lancet Oncol 2015;16:e93-e100.

111. Komatsu S, Fukumoto T, Demizu Y, Miyawaki D, Terashima K, Sasaki $R$, et al. Clinical results and risk factors of proton and carbon ion therapy for hepatocellular carcinoma. Cancer 2011;117:4890-4904.

112. Qi WX, Fu S, Zhang Q, Guo XM. Charged particle therapy versus photon therapy for patients with hepatocellular carcinoma: a systematic review and meta-analysis. Radiother Oncol 2015;114:289-295. 